\section{Declaration of interest}

None.

original

papers

\section{Acknowledgements}

I thank Ann Emmerton, Pat Welsh, Pam Currey, Catherine Bell, Richard Harrison, Peter Thompson, Pam Stephenson, Apsara Pannikar and Alan Thomas from the Department of Old Age Psychiatry, Bensham Hospital.

\section{References}

COMMITTEE ON SAFETY OF MEDICINES (2004) Message Sent to Healthcare Professionals. http://

www.mhra.gov.uk/home/ idcplg?ldcService=SS_GET_PAGE \&useSecondary=true\&SSDocName $=$ CON1004298\&ssTargetNodeld $=221$

FINKEL, S., KOZMA, C., LONG, S., et al (2005) Risperidone treatment in elderly patients with dementia: relative risk of cerebrovascular events versus other antipsychotics. International

GILL, S. S., ROCHON, P. A., HERRMANN, N., et al (2005) Atypical antipsychotic drugs and risk of ischaemic stroke: population based retrospective cohort study. BMJ, 330, 445 .

HERRMANN, N. \& LANCTOT, K. L.

(2005) Do atypical antipsychotics cause stroke? CNS Drugs, 19, 91-103. Psychogeriatrics, 17, 617-629.
HERRMANN, N., MADAMI, M. \& LANCTOT, K. L. (2004) Atypica antipsychotics and risk of cerebrovascular accidents. American Journal of Psychiatry, 161, 1113-1115.

LIPEROTI, R., GAMBASSI, G., LAPANE, K. L., et al (2005) Cerebrovascular events among elderly nursing home patients treated with conventional or atypical antipsychotics. Journal of Clinical Psychiatry, 66, 1090-1096.

MORETTI, R.,TORRE, P., ANTONELLO, R. M., et al (2005) Olanzapine as a possible treatment of behavioural symptoms in vascular dementia: risks of

cerebrovascular events. A controlled open-label study. Journal of Neurology, 252, 1186-1193.

MOWAT, D., FOWLIE, D. \& MACEWAN, T. (2004) CSM warning on atypical antipsychotics and stroke may be detrimental for dementia. BMJ, 328, 1262.

PERCUDANI, M., BARBUI, C., FORTINO, I., et al (2005) Second-generation

antipsychotics and risk of cerebrovascular accidents in the elderly. Journal of Clinical Psychopharmacology, $\mathbf{2 5}$ $468-470$

ROYAL COLLEGE OF PSYCHIATRISTS FACULTY FOR THE PSYCHIATRY OF OLD AGE (2004) Atypical Antipsychotics and Behavioural and Psychiatric Symptoms of Dementia. Prescribing Update for Old Age Psychiatrists. http://www.rcpsych.ac.uk/pdf/ Atypicalguidance.pdf

SCHNEIDER, L.S., DAGERMAN, K. S. \& INSEL, P. (2005) Risk of death with atypical antipsychotic drug treatment for dementia: meta-analysis of randomised placebo-controlled trials. JAMA, 294, 1934 -1935.

SUH, G. H. \& SHAH, A. (2005) Effect of antipsychotics on mortality in elderly patients with dementia: a 1-year prospective study in a nursing home. International Psychogeriatrics, 17 429-441.

Karen L. Franks Specialist Registrar in Old Age Psychiatry, Bensham Hospital, Gateshead,Tyne andWear NE8 4YL, e-mail: klfranks@doctors.org.uk

\title{
Correspondence from substance misuse services - what do general practitioners really want?
}

\section{AIMS AND METHOD}

To improve the quality of correspondence by identifying what general practitioners (GPs) regarded as the important attributes in patient letters from a substance misuse service. A postal questionnaire survey was carried out to determine the views of general practitioners in Brighton and Hove City.

\author{
RESULTS \\ Responses were obtained from \\ 32 out of 45 GP surgeries ( $71 \%$ ) \\ and indicated that correspondence \\ should be prompt, concise and \\ regular. An assessment summary, \\ management plan and clear \\ medication prescribing \\ arrangements between \\ primary and secondary services
}

\author{
were considered particularly \\ important.
}

\section{CUINICAL IMPLICATIONS}

New quality standards for correspondence to GPs have been implemented by the Brighton Substance Misuse Service. These might be of interest to other such services.
Good-quality correspondence between specialist services and general practitioners (GPs) is fundamental to patient care. However, the standard of such correspondence does not always meet with GPs' expectations (White \& Marriott, 2004). Scott et al (2004) identified a number of highly desirable attributes of letters from specialists to GPs across a range of medical disciplines. These included diagnostic formulations, management regimes, use of clinical evaluations, prognostic statements, contingency plans and follow-up arrangements. Others (Dunn \& Burton, 1999; Reynolds, 1999) have also distilled important components of correspondence from mental health services (diagnosis, presenting complaint, drug treatment, management plan, follow-up arrangements, mental state and prognosis). However, we were unable to find any studies of written communication between substance misuse services and GPs.

The aim of this study was to identify what GPs regarded as desirable components and attributes of correspondence from our substance misuse service. It was intended that information gleaned from the survey and by other methods would help improve the quality of the service's written communication.

\section{Method}

Brighton and Hove City is a seaside resort with a population of 260000 served by 45 separate general 
Table 1. Desired attributes of correspondence from substance misuse services ( $n=32$ practices)

\begin{tabular}{|lc} 
Attribute & $\begin{array}{c}\text { Number of } \\
\text { respondents, } \\
n(\%)\end{array}$ \\
\hline Content & \\
Patient details & $2(6)$ \\
Confirmation of attendance & $6(19)$ \\
Summary of assessment & $17(53)$ \\
Management plan & $17(53)$ \\
Any medication issues & $22(69)$ \\
Details of drugs to be prescribed & $11(34)$ \\
Who should prescribe what? & $13(41)$ \\
What GPs should not prescribe & $8(25)$ \\
Benzodiazepine prescribing & $6(19)$ \\
Notification of change in medications & $6(19)$ \\
Laboratory results & $7(22)$ \\
Prognosis & $1(3)$ \\
Risk issues & $4(13)$ \\
Named contact person & $8(25)$ \\
Follow-up arrangements & $8(25)$ \\
Reason for discharge/cessation of treatment & $9(28)$ \\
Format & \\
Brief/succinct & $16(50)$ \\
Timely & $8(25)$ \\
Regular update reports & $8(25)$ \\
Good English/writing & $2(6)$ \\
\hline
\end{tabular}

GP, General practitioner

1. Many respondents made more than one comment on medications.

practices. The city has a well recognised intravenous drug problem and has, for a number of years, attracted attention because of its high level of drug-related deaths (Hickman et al, 2004).

A postal questionnaire survey of general practices in Brighton and Hove City was undertaken in June 2005. For each practice a single senior representative (e.g. senior partner) was selected for inclusion and contacted by post. A cover letter explained the rationale of the survey and requested the recipient's cooperation. Questionnaires were sent out in two phases, with non-respondents contacted by a single telephone call 2 weeks later.

The study questionnaire contained a single open question, 'What do GPs want in correspondence from the substance misuse service?' A small list of prompts invited possible consideration of issues such as timeliness, length, style, structure and content. A single blank A4-size space was provided for free-text responses. An undertaking was given that no individual practice or practitioner would be identified in any published findings.

\section{Results}

Of the 45 practices targeted, 32 returned completed questionnaires, representing a $71 \%$ response rate. Relevant individual comments on returned questionnaires were then categorised in an attempt to identify common
Box 1. Quality standards for correspondence from substance misuse services to general practitioners

Format

- Correspondence should be concise, prompt and regular

- GPs should receive a letter within 2 weeks of patient assessment/discharge

- GPs should receive updates at least every 3 months and at times of significant change

- Where possible correspondence should be limited to a single page.

Content

- Summary of assessment

- Management plan

- Details of medication and prescribing arrangements (who is prescribing what and what's not to be prescribed)

- Risk issues

- Named contact person

- Follow-up arrangements

- Notification of reasons for discharge from treatment.

1. GPs, general practitioners

themes that emerged from the large number of varied responses. These major attributes and components of correspondence to GPs thus identified are presented in Table 1.

\section{Discussion}

The $71 \%$ response rate is comparable to that of similar questionnaire surveys of GPs (Reynolds, 1999) and suggests that general practice colleagues are interested in improving communication between primary and secondary care.

Predictably, and in keeping with previous studies, our GPs identified a summary of assessment, management plan and details of medication, a contact person and follow-up arrangements as most desirable attributes of correspondence from the substance misuse service. Shorter correspondence does not appear to necessarily result in loss of information (Blakey et al, 1997) and our GPs placed particular emphasis on brevity, timeliness and frequency of written correspondence.

By far the most frequent comments related to medication. Specifically GPs wanted to know what medications were to be prescribed by the substance misuse service, what medications were to be prescribed by the GP and, equally importantly, what medications GPs should not prescribe for patients. This appeared to be particularly pertinent in the case of benzodiazepine prescribing. Such emphasis on clear communication around prescribing arrangements and responsibilities is apt in view of some patients' drug-seeking behaviour and the need to avoid the potentially serious problem of 'double scripting'.

A large number of respondents wanted not only notification of but also reasons for discharge of patients from specialist services. This probably reflects an original papers 
increasing propensity of some GPs to 'take on' and prescribe for patients who have failed with (or been failed by!) secondary services.

The Brighton and Hove Substance Misuse Service has now implemented the survey findings into new service standards and guidelines on the quality, frequency and content of future correspondence to GPs (Box 1). Despite an acceptable response rate, our results may not be generalisable elsewhere but our study might merit replication by other drug services.

\section{Conclusions}

Overall GPs view brief, timely and regular correspondence from substance misuse services as important. They placed particular importance on information with regard to medications being prescribed and required clear delineation as to what medications ought and ought not to be prescribed for patients by their GPs.

\section{Declaration of interest}

None.

\section{Acknowledgements}

We thank Ms Amanda Brookman, Clinical Librarian, Brighton and Sussex University Hospitals NHS Trust and our GP colleagues for their assistance.

\section{References}

BLAKEY, A., MORGAN J. \& ANDERSON, REYNOLDS, D. (1999) GPs' views on I. (1997) Communications between GPs discharge summaries and new patient and psychiatrists: the long and the assessment letters. Psychiatric Bulletin short of it. Psychiatric Bulletin, 21, 622-624.

DUNN, J. \& BURTON, S. (1999) GPS views on discharge summaries. Psychiatric Bulletin, 23, 355-357.

HICKMAN, M., HIGGINS, V., HOPE, V., et al (2004) Injecting drug use in Brighton, Liverpool and London: best estimates of prevalence and coverag of public health indicators. Journal of Epidemiology and Community Health, $\mathbf{5 8 , 7 6 6 - 7 7 1 . ~}$
SCOTT, A., MITCHELL, C. \& LOGANE. (2004) An audit of consultant physicians' reply letters for referral to clinics in a tertiary teaching hospital. Internal Medicine Journal, 34, 31-37.

WHITE,T. \& MARRIOTTS. (2004) Using evidence-based dissemination and mplementation strategies to improve routine communication between general practitioners and community mental health teams. Psychiatric Bulletin, 28, 8-11.

Devatha Radhae Shyam Specialist Registrar, Substance Misuse Service, South Downs Health NHS Trust, Brighton, *Hugh Williams Consultant Psychiatrist, Substance Misuse Service, South Downs Health NHS Trust, 26 Ditchling Road, Brighton BN1 4SF and Honorary Senior Lecturer, Department of Addictive Behaviour and Psychological Medicine, St George's Hospital Medical School, London SW17 ORE, e-mail: hugh.williams1@sussexpartnership.nhs.uk

\section{Screening for smoking and substance misuse in pregnant women with mental illness}

\author{
AIMS AND METHOD \\ Smoking and substance misuse \\ adversely affect the outcome of \\ pregnancy and psychiatric patients \\ are known to smoke more than other \\ patients. Data collected at the time of \\ routine antenatal booking were ana- \\ lysed to investigate whether preg- \\ nant women with mental health \\ problems smoke more than other \\ pregnant women.
}

\author{
RESULTS \\ Data were collected from 156 women. \\ Those with a psychiatric diagnosis \\ $(n=76)$ were significantly more likely \\ to smoke $(P<0.001)$. Associations \\ were also found with illicit drug use \\ and previous termination of preg- \\ nancy. The most common psychiatric \\ diagnosis was depression (62\%). A \\ diagnosis of schizophrenia was not \\ recorded for any of the women.
}

\author{
CLINICAL IMPLICATIONS \\ The strong association between \\ smoking and psychiatric diagnosis \\ results in an increased risk of obste- \\ tric complications in psychiatric \\ patients. Anti-smoking interventions \\ might be delivered by adequately \\ trained midwives and opportunisti- \\ cally during contact with mental \\ health professionals.
}

Smoking and substance misuse during pregnancy are known to adversely affect foetal outcome by a reduction in birth weight associated with intra-uterine growth retardation, preterm birth and an increased rate of perinatal death (Bennedsen, 1998). It is also known that psychiatric patients smoke more than other patients or the general public (McCreadie, 2002) and that women with schizophrenia have an increased risk of obstetric and perinatal complications (Sacker et al, 1996; Bennedsen, 1998; Howard et al, 2003). This increased risk has not been definitively accounted for; it is not known whether lifestyle differences such as smoking and substance misuse are explanatory, whether psychotropic medication is the causal factor or whether it is a result of genetic factors. There is only limited evidence supporting the assertion that pregnant women with mental illness are more likely to smoke and misuse substances than other pregnant women (Maughan et al, 2004), so we decided to investigate this at a routine antenatal clinic. 